University of Nebraska - Lincoln

DigitalCommons@University of Nebraska - Lincoln

To Improve the Academy

Professional and Organizational Development

Network in Higher Education

1996

Designing, Implementing and Assessing a University TechnologyPedagogy Institute

Devorah A. Lieberman

John Reuter

Follow this and additional works at: https://digitalcommons.unl.edu/podimproveacad

Part of the Higher Education Administration Commons

Lieberman, Devorah A. and Reuter, John, "Designing, Implementing and Assessing a University Technology-Pedagogy Institute" (1996). To Improve the Academy. 358.

https://digitalcommons.unl.edu/podimproveacad/358

This Article is brought to you for free and open access by the Professional and Organizational Development Network in Higher Education at DigitalCommons@University of Nebraska - Lincoln. It has been accepted for inclusion in To Improve the Academy by an authorized administrator of DigitalCommons@University of Nebraska - Lincoln. 
Lieberman, D.A., \& Reuter, J. (1996). Designing, implementing and assessing a university technology-pedagogy Institute. In L. Richlin (Ed.), To Improve the Academy, Vol 15 (pp. 231-249). Stillwater, OK: New Forums Press and the Professional and Organizational Development Network in Higher Education. Key words: Faculty Development Programs, Instructional Development Programs, Instructional Technology.

\section{Designing, Implementing and Assessing a University Technology-Pedagogy Institute}

\section{Devorah A. Lieberman}

\section{John Reuter}

Portland State University

This article describes two models for designing and implementing technology-pedagogy institutes as part of university wide faculty development. Each model contains similar learning objectives for Institute participants, yet describes different institute designs. The authors describe the strengths and weaknesses of each model as learned through assessment evidence gathered during institutes on their campus. Assessment of student learning in relation to technology introduced within the class is discussed. Suggestions for more effective Institutes and assessment tools are addressed.

During this time of diminishing resources, campuses of higher education are seeking more efficient and effective methods for disseminating information in the classroom . Implemented appropriately, incorporating technological enhancement into the classroom context 
may be one of the most powerful tools for improving learning outcomes. Technological pundits assert that a technologically-enhanced learning environment "attempts to stimulate classroom activity by demonstrating and using software or tools specific to a particular discipline, by promoting high levels of interaction among students and faculty, and by involving students in simulated activities or data-gathering via the Internet and remote databases" (Shapiro, Roskos \& Cartwright, 1995, p. 67). Investigating the veracity of this claim, campuses around the globe are involved with faculty development in the area of technology in both traditional and virtual classrooms. Some campuses are forming faculty task forces to address the issue, others are offering faculty development through technology centers, others are convening discussion groups, and others are designing campuswide technology-pedagogy models (Center Associate, 1994). Whatever path an institution embarks upon, it is the effective incorporation of technology into the classroom that is the ultimate goal (Liberal Education: Technology in Context, 1995).

This article describes two campus-wide institute models that address the uses of technology in the classroom. Both Institutes were designed, attended and facilitated by Portland State University faculty. This article will provide a basic approach for others who are in the process of exploring ways to address pedagogy and technology as interrelated issues. Each institute offers a different format in an attempt to meet similar learning objectives. Assessment issues are addressed and discussed in terms of instructional technology and learning outcomes for students in the classroom.

\section{Meeting the Need for Training Faculty at the University Level}

The Portland State University Center for Academic Excellence recognized the need for value-added pedagogy through greater use of technology in the university classroom and developed a strategy for motivating faculty to a) bring technology into their classroom presentations; b) design interactive software as a teaching strategy and a means for students to learn technology themselves; c) share their pedagogical technological tools with colleagues; and, in addition to c) 
recruit faculty to help develop colleagues' technological/pedagogical knowledge and application capabilities. The guiding philosophy for the technological/pedagogical faculty development was that all actions would be suggested, developed, delivered, and assessed by faculty. Thus, the process began...

January 1995, The Center for Academic Excellence invited a faculty member (who is a co-principal investigator for a "technology in the large classroom" grant for faculty development) to become the Center's faculty-in-residence for the academic year 1995-1996. When he became an active part of the Center in spring, 1995, he designed a plan which included his mission statement, goals, objectives and activities for the upcoming year. Included within this document were the means to assess the effect of his programs on the university faculty, their teaching, and student learning. The plan included technology roundtables which met over the 1995 spring quarter with faculty members who then identified the current status of technology in the classroom at the university, long-term objectives, and obstacles faculty face in terms of those identified long-term goals. The university roundtables were designed after the American Association for Higher Education (AAHE) Technology Roundtable model designed by Stephen Gilbert and introduced in the January 1995. The Center sent the faculty-in-residence and two other faculty members to the AAHE Technology Roundtable in order to establish the PSU roundtable core participants and to begin a long-term technology roundtable process at our University.

The PSU technology roundtables convened three times during the 1995 spring term, inviting participants from across disciplines, with diverse technological expertise. Based upon these three technology roundtables, the following needs were identified for PSU instructors.

1. Tenured and untenured instructors should have multiple opportunities to be computer literate.

2. They should be able to use technology to enhance the learning of their students in the classroom environment.

3. They should be able to design technologically based learning activities where appropriate to enhance student learning.

With these suggestions in mind, the Center's director for Teaching \& Learning Excellence and the faculty-in-residence wrote a proposal 
outlining a suggested University Summer 1995 Technology Institute. A detailed explanation of the process for developing the initial technology Institute and a subsequent Institute follows with data addressing the objectives for each Institute.

\section{The Summer Technology Institute}

The Summer Technology Institute was designed to meet the technological and pedagogical needs of at least 20 faculty on campus. Participants who successfully completed the one week technologypedagogy instruction phase and presented a follow-up project to their fellow Institute participants would receive their choice of either a laptop computer or Power book to remain in their possession or the remainder of their tenure at the university. Table 1 describes the learning objectives for each faculty who participated in Phase One of this Institute.

\begin{tabular}{|l|} 
TABLE 1 \\
Phase One Institute Objectives \\
\hline As a result of completing Phase One of the Institute each participant should \\
be able to: \\
\hline Apply eight broad categories of technology applications in the classroom context: word \\
processing, presentation software, graphics software, Internet access, interactive \\
multimedia, electronic mail, and visualization tools; \\
Identify students' needs and which technology applications may best meet these needs; \\
Design course syllabi with goals, objectives and activities induding the use of technology \\
to enhance student learning of course content; \\
Design an example project incorporating technology enhance student learning which will \\
be presented six weeks subsequent to Phase One of the Institute.
\end{tabular}

Each participant was expected to complete the following three phases of the Summer Technology Institute:

Phase One was the one-week seminar intensive technology-pedagogy instruction.

Phase Two occurred six weeks following the completion of the one week Institute. Each participant presented a project that incorporated technology introduced at the Institute to their fellow Institute members. They accompanied the presentation of technology with an 
explanation of why they chose this particular teaching mode and how it may be more effective for learning than the traditional lecture style in teaching. Other participants offered suggestions and helpful comments.

Phase Three required participants to present their technology/pedagogy project to two university-wide colloquia during the 1995-1996 academic year.

Assessment design was critical for this project. We anticipated that assessment would address two primary issues: a) the effects upon participants during the Institute, in terms of what they learned and what they felt they could apply to their teaching after the Institute concluded and b) the learning outcomes for their students in relation to presenting classroom materials through technological applications within the classroom setting.

\section{Selecting Summer Institute Participants}

Each full time instructor and faculty member at the University received a Call for Summer Institute Participation. Interested individuals contacted the Center and received an application. The application asked for self-evaluated levels for the following abilities: word processing, presentation tools, graphics, Internet and interactive tools. Each applicant also was asked to describe a technology-based project to be used in the classroom environment, as well as a description of student learning assessment in relation to the project described.

Criteria for participant selection were established. The criteria were: a) number of students taught (and size of class) each academic year; b) levels of conceptual and performative knowledge (low, medium, high); c) quality of a proposed technology/pedagogy project; and d) quality of assessment designed. Conceptual levels related to understanding the particular technology applications. Performative levels were related to abilities to use the applications in a classroom setting.

Seventy-eight eligible faculty submitted applications. Twenty participants were selected. Preference for selection was given to applicants with larger classes and more students per year, higher quality of project and assessment tool described. The selection com- 
mittee attempted to select participants who represented each of the levels of conceptual and performative technology knowledge levels. We expected those with the greatest knowledge would be able to mentor those with lesser conceptual and performative levels. And, long term, those with less knowledge might become earlier adopters of technology in the classroom than if they had not this Institute opportunity.

\section{The Summer Institute Design}

Phase One of the Summer Technology Institute was offered as two identical sessions in order to meet the time preferences for the participants. Each session spanned five days, four hours of in-class instruction and interaction per day. Participants were expected to spend the needed hours after each scheduled class to practice the applications introduced during the sessions.

Each day focused on specific learning objectives for the Institute participants. On the first day, Institute participants were introduced to Internet and the World Wide Web. This introduction allowed them daily to log into the Center for Academic Excellence Homepage which included The Summer Technology Institute Hypertext. Thus, each day when the participants entered the computer laboratory they logged onto the Institute Homepage and previewed daily objectives and activities. This allowed each participant to "walk the talk" and experience Internet tools that they could then incorporate into their future classes.

Faculty proficient at incorporating technology into their teaching were hired to teach or act as resources in the Institute. These faculty instructed in Powerpoint, Digital Chisel, Astound, Adobe Works, SuperPaint and the Internet. Technologically competent students at the university were hired to float among the participants and offer help as needed. Day One and Day Four activities included learning style, teaching style, and student centered teaching exercises.

All Institute instruction was held in the Visual Instruction Laboratory, designed for computer instruction. It houses 11 computer stations configured in a " $U$ " shape. Thus, individuals can communicate with those on either side or across. The instructor's computer is 
placed at the open end of the " $U$ " and is connected to the projection equipment. This allows all participants to view easily the instructor and the large. As each application is introduced, the instructor can demonstrate the program capabilities on the screen in front of all the participants. Then, the participants can practice the applications individually at their stations. The instructors can easily circulate among participants to answer questions and offer advice.

\section{Assessment}

The Summer Technology Institute was assessed for several different objectives. Assessment instruments were developed to measure: a) change in participants' understanding of the technology applications introduced during the Institute; b) change in participants' abilities to perform the technology introduced during the Institute; c) change in kinds of questions asked about technology introduced in the Institute to pedagogical applications; d) frequency and degree of technology integrated into course curriculum; and e) student feedback on the learning related to technology in the classroom.

\section{The One Week Institute-Participant Progress}

On the first day of each Institute the participants completed a baseline self-assessment of their conceptual knowledge and performative skills on the following forms of technological applications: word processing, graphics, interactive multimedia, presentation packages, and Internet. These data were compiled as descriptive data. On the fifth and final day of Phase One of the Institute, the 20 participants completed the same self-assessment. Table Two represents the descriptive statistics of the first and second assessment of both conceptual and performative knowledge and skills.

At the close of each of the five instruction days, each participants completed a questionnaire. Three questions were asked:

1. What questions did you have during the class today?

2. How were your questions answered?

3. What questions do you still have that were unanswered? 


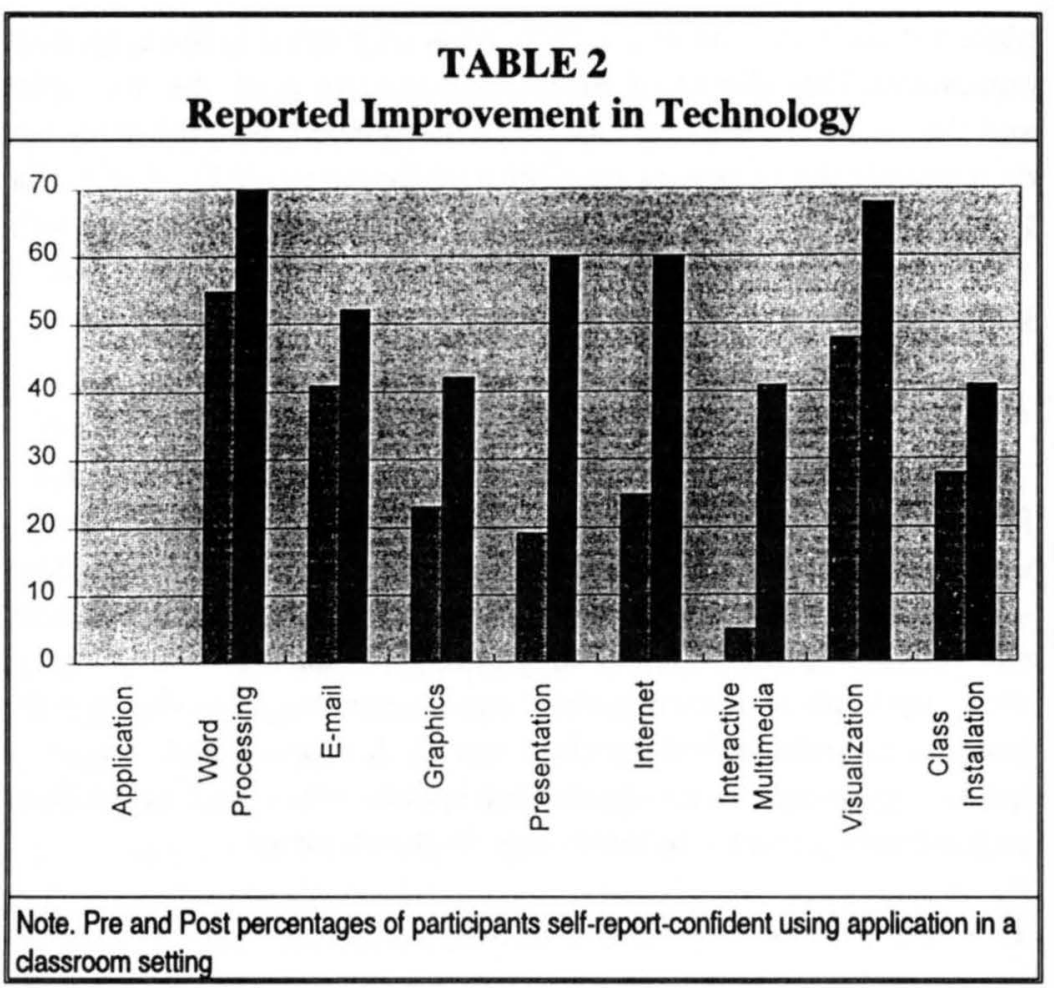

These questions were analyzed throughout the week establishing the depth of participant questions, the relationship questions had with their pedagogical issues, and, where they sought answers to their questions. Patterns in the questions emerged throughout the week. The first day, most questions had to do with technological issues. The technological questions concerned differences between MAC and DOS operating systems, basic word processing questions, and power point presentations. Participants generally cited the facilitators as the ones who provided the answers. The unanswered questions generally addressed not having enough attention to understand a step-by-step process to a particular application.

As the week continued, more of the technological questions were answered by fellow-participants or the student helpers. Participants who expressed the most frustration about learning the basics of the applications also expressed the need for a step-by-step learning proc- 
ess that might be best learned through repeated practices. Several participants commented in their daily feedback forms that they were not comfortable playing to learn the process and felt uncomfortable not knowing the exact process for executing an application.

As the week progressed, there were significantly more questions about imbedding technology as value-added into the student learning context. These questions were answered through group interaction. However, the questions that were cited as unanswered by fellow participants concerned specific student learning situations or contexts. For example, participants' comments included, "I still need advice on how to introduce email as the best tool for a statewide distance learning program," and "How do I make the technology interactive in a class of two hundred students?"

\section{Phase Three Assessment}

During Phase Three of the Institute, each participant was expected to present two colloquia across campus displaying the project they designed during Phase One. We expected the participants to schedule colloquia within their departments and interdepartmentally. This part of the Institute was the least successful as no colloquia were scheduled. When we asked participants why they had not scheduled any colloquia they said that the department could not find the time for their presentations or that they did not feel comfortable presenting to colleagues in their departments

One of primary assessment issues addressed concerned student reports about the use of technology in the class and how it related to learning. The Institute directors asked each participant for permission to come to classes where they had integrated technology into the teaching and students would complete surveys asking about effects of technology in the class. The directors were invited into 10 of the 20 classes. Three participants did not respond, three participants said they had not used the technology in the class that term, and four participants said they did not have time at the end of the term to survey the class. Four questions comprised the survey:

1. What were ways that technology was used to present information in this class? 
2. What other ways was technology used for learning in this class?

3. How do you think your learning may have been enhanced by the use of technology in this class?

4. What ways would you like to see technology used in your classes in the future?

The most commonly used instructional technologies reported by the students were electronic mail, Internet, and Powerpoint presentations. Students who were required to use Internet or to create a Homepage within the class reported the greatest enhancement of learning. The most frequently expressed negative opinion about the use of technology in the class was that it may have been used too often. Several students reported that their professors relied on Powerpoint or a presentation tool when there could have had greater personal interaction with the students. The trend that seemed to emerge was that those professors who received the most negative comments from students were those who used almost no instructional technology or who overused presentation tools in their classes rather than when it would be the most advantageous to the students' learning.

\section{The Directors' Analysis of the Strengths and Weaknesses of the Summer Technology Institute}

After the completion of the Institute and the follow-up assessment, it came time to analyze the strengths and weaknesses in relation to planning a Winter Technology Institute for Winter Break in December 1995. These results would suggest what should and should not be replicated for the Winter Institute. The primary findings were:

1. In-class participant interaction is essential.

2. Participant mentoring around technology is well-received by fellow-participants.

3. More time was needed for group interaction around pedagogical issues.

4. Participants needed to be more organized around their own pedagogical goals. In other words, if a participants perceived that time spent addressing a particular technology was not useful for their own pedagogical goal, then this was not time well-spent for them. 
5. More support staff is needed for those who require individual assistance.

6. Phase Three presentations forced participants to reach closure on their suggested projects, present quality work in front of colleagues, pilot the project they would present in class, and receive valuable feedback from their colleagues.

7. The Powerbook or Laptop was not what was most needed by all of participants.

8. Ongoing individual support was needed for some of the participants after the Institute ended.

9. Institute participants did not use the technology listserv as a support system for technology questions or feedback on issues.

10. Some participants with the least knowledge entering the Institute did not maintain their enthusiasm for technology and pedagogy.

11. Some participants with the least knowledge entering the Institute became high integrators of technology and pedagogy.

12. The university-wide colloquia were difficult to organize by the Center and, was not easily initiated by the participants.

13. Drastically different technological abilities could be inhibiting for individuals within the group.

\section{The Winter Technology Institute}

Based upon the lessons gained from the Summer Technology Institute, the Winter Technology-Pedagogy Institute was designed and implemented. The primary differences between the two Institutes centered around: a) use of time during the Institute; b) theme team formation; c) presentation of group project and individual project; d) use of listserv as a teaching tool; e) follow-up participant interaction; and $f$ ) Institute participation incentives.

The Winter Technology Institute included three phases: Phase One was the Institute; Phase Two, the group and individual project presentation; and, Phase Three was all follow-up activities coordinated by the Center for the Institute participants (which included Summer and Winter Technology Institute participants). Incentives offered to these participants included a $\$ 1500$ stipend for completion of the program. The stipend monies were to be used to purchase 
hardware or software that would be used by the participant and inventoried through the university.

\section{Selecting Winter Institute Participants}

The call for Winter Technology Institute applications was disseminated across campus. The completed applications allowed the Institute directors to ascertain level of technological knowledge of each participant as well as their pedagogical interests and expressed outcome for tools gained through the Institute. Twenty participants were accepted into the Institute. Based upon pedagogical interests, suggested technology-pedagogy project, and level of technological knowledge, participants were assigned to one of six themes: distance learning-WWW; multicultural pedagogy; team teaching; simulations; the large classroom; or computer based training.

This Institute was designed so that individuals could accomplish three objectives: a) discuss common pedagogical issues around integrating particular technologies into their curricula; b) help each other to learn the technological tools; and, c) choose to attend the Institute workshops most appropriate to their individual and team needs.

\section{The Winter Institute Design}

Each participant was assigned to one of the six themes, based on their interest in designing their project, and met with their fellow theme members throughout the Institute. Also, the Institute directors attempted to have "levels of technological expertise" represented within each team. Thus, each team would have early technology adopters and late technology adopters with the intent that the early adopters would serve as resources for the late adopters.

Phase One of the Institute was designed to span six eight-hour six days. All Institute participants were expected to attend all activities during the first two days. Technology/pedagogy workshops were offered during the last four days. Participants were expected to attend those workshops which most addressed their particular needs. Theme teams were expected to meet during the six days at times agreed upon by each theme team. Phase Two of the Institute occurred three weeks after Phase One. The participants reaggregated for one afternoon 
session and one morning session. During this session each Theme Team made a presentation to the whole group addressing technological and pedagogical concerns about their theme. For example the "World Wide Web" theme talked about the advantages and the potential pitfalls to course objectives and learning outcomes in using distance learning in their classes. Following the theme presentations, each individual presented the project they had worked on during Phase One and during the subsequent three weeks.

The first two days of the Institute, when all participants were present, very little theme team interaction occurred. Mini-demonstrations of tools that would be offered in half-day workshops over the next five days were presented and there were discussions addressing issues of pedagogy, technology, learning styles and curriculum design. Selected participants from the Summer Technology Institute were invited to present projects they designed to the Winter Technology Institute participants.

At the end of the second day, individuals had chosen preferences for workshops they would like scheduled during the following five days. It was critical that the campus coordinator for instructional technology be part of the planning for this process. Based upon the needs expressed by the Institute participants, he coordinated workshops to meet the participants' needs. Faculty who participated in the Summer Institute or individuals who currently teach in the Office of Instructional Technologies were enlisted to teach the various workshops. Participants chose to attend those workshops that they felt addressed their needs for their project completion.

\section{Winter Institute Communication and Resources}

The Summer and Winter Technology Institute participants each were enrolled on a technology listserv. This listserv served two purposes: to disseminate information about upcoming events and activities effecting the Institute participants schedules, etc. and to serve as a resource for participants. They asked questions and solved technology and pedagogy problems they were having among themselves on this listserv.

The Instructional Computing Center is open five days a week, 
eight hours per day. Employees in this Center were able to oversee all the Institute workshops and provide support staff to help individuals during the workshops, between workshops, outside of workshops and between Phase One and Phase Two of the Institute. They have continued to provide technological support for Institute participants long after the Institute has ended.

\section{Self-Reported Improvement}

The self-reported average percentage increase for Winter Technology Institute participants by application is reported in Table Three. The greatest self-reported technological increase was in presentation applications (50\%) and classroom installation (19\%). All participants were required to make a Powerpoint presentation with their theme teams and each participant will need to know how to use the technology in the classroom setting. The participants' self-reported improvement throughout the Institute suggests that on average across applications there was improvement. It is noteworthy that the one application (Powerpoint) that each applicant was required to use for their theme team presentation reported the greatest increase in improvement $(50 \%)$.

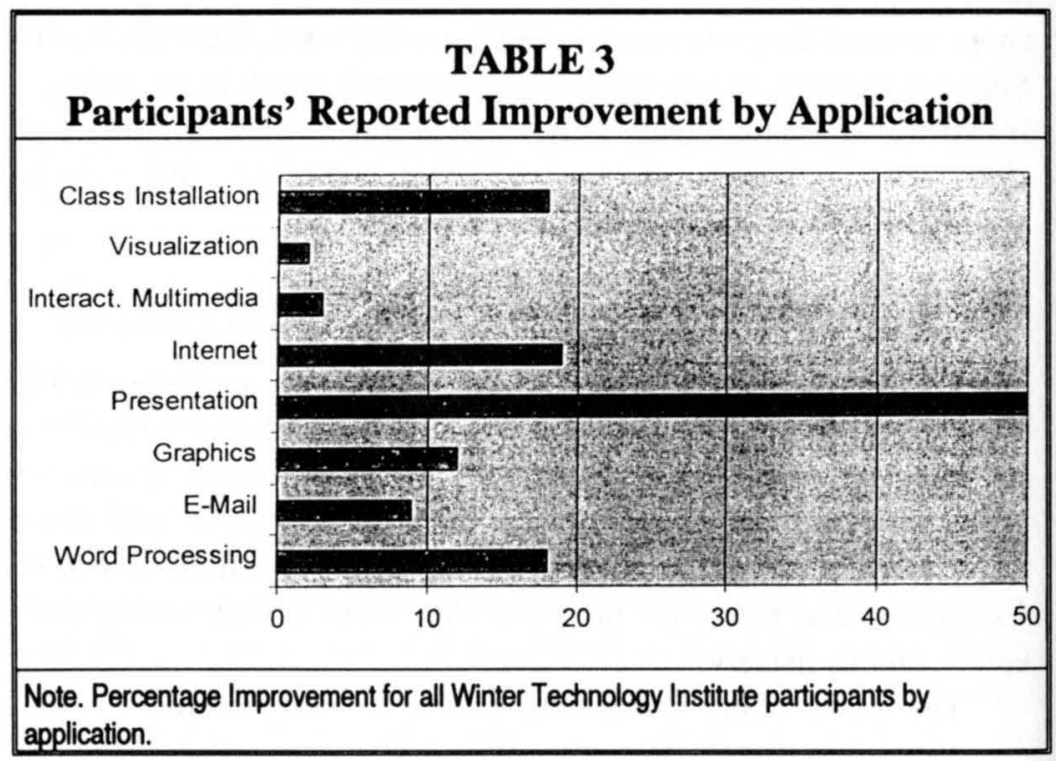




\section{Formative Assessment of the Winter Technology Institute}

Overall, participants expressed a positive response to the format of the Institute and the content offered. The theme teams were considered successful as the team was able to address technological and instructional issues that were relevant to that particular theme topic. Also, the themes had the opportunity to share their conclusions via a technological presentation with their fellow Institute participants. Also, individuals within each theme used each other as resources to understand the technology presented within the Institute workshops and as further help after Institute hours and during the three week break between the Institute workshops and the project presentation date. Three criticisms emerged from the participant assessment surveys: First, more time was needed as a whole group to discuss pedagogical issues in relation to bringing the technologies into teaching; second, learning styles of students within the classes in response to using technology in their learning needed to be addressed in greater depth; and, third, too much information was addressed during the Institute. Workshops could have been offered in greater depth and for longer periods of time. It was difficult for those participants who needed closer instruction to receive it during a time restrained workshop.

\section{Follow-up Activities}

\section{Technology Fair}

Three weeks after the completion of the Winter Technology Institute, The Center for Academic Excellence and Academic Affairs hosted a Technology Fair for all faculty and staff at Portland State University. This activity was included in the campus-wide winter convocation. Summer and Winter Technology participants were invited to exhibit their Institute projects using a laptop or Powerbook computer. Twenty-five participants chose to exhibit their projects. Approximately 300 faculty and staff attended the fair and interacted with the technology participants. Feedback from the technology fair addressed the pride that the technology participants took in sharing 
their projects with their colleagues within and outside their own disciplines.

\section{Technology Institute Listserv}

The Technology Institute listserv serves as a follow-up activity. It acts as both an announcement bulletin board and as a resource for participants. When individuals want to announce an activity or piece of information they feel is of interest to the other participants, it is put on the listserv. When individuals have a technology or pedagogy question, it is put on the listserv and the other participants serve as resources for answers.

\section{Monthly Technology Institute Reunions}

The Center for Academic Excellence hosts monthly reunions for all the Summer and Winter Institute Technology participants. A regularly scheduled 90 minute reunion is held the last Wednesday of the month. The purpose of the reunion is to share personal stories about the use of technology in the classroom, to present new technological applications to the participants, to share technology assessment models, and to problem solve technology-pedagogy issues that arose during the month. If a technological application is presented during the reunion, time is spent discussing the various pedagogical uses of the application. For those interested in exactly "how to" perform the technological tasks associated with the application, a "hands-on" follow-up meeting is scheduled.

Presently, two major topics are part of the reunion discussions. First, rather than the Institute directors managing the assessment of technology-pedagogy effects, the Institute participants are exploring and designing various assessment models to use in their own classes. These assessment strategies range from Classroom Assessment Techniques (Angelo \& Cross, 1993) to end-of-the-term summative assessment. Second, the Institute participants are interested in compiling a technology-pedagogy book including a chapter for each participant's discipline-specific based project, how it was designed, how it was presented in a class setting and the student assessment feedback. 


\section{Teaching and Technology Roundtable}

Monthly, the Center hosts a roundtable session open to all faculty and staff across campus. The roundtable sessions are advertised with topics addressing technological issues of concern to the PSU campus. Examples of recent roundtable topics are: The Large Classroom and Technology, Infrastructure Support and Technology, Learning-Styles and Learning Technology, Using "The First Class Email" system. Institute participants are encouraged to attend the roundtable sessions.

\section{Websters}

Once a month, a two-hour session is held solely to address issues around Internet and the World Wide Web. The first hour is always introductory, teaching attendants how to navigate the Web and uses for the Web in teaching. The second hour addresses how to make a Homepage and more advanced uses of the Web. Institute participants are encouraged to attend these sessions.

\section{Random Technology-Pedagogy Workshops}

Throughout spring term 1996, there have been weekly two-hour technology-pedagogy sessions that address pedagogical issues and various technology applications appropriate for each situation. Examples of the sessions are: How to use Powerpoint to enhance your class presentation, Facilitating classroom discussion by using inspiration, Using E-mail as an in-class and out-of-class tool, Using the Web to find information you could otherwise not bring into class, Presenting information in class using Excel." Institute participants are encouraged to attend any of the random workshops they choose.

\section{Future Institutes}

Learning from the participants' responses during and after each technology Institute has defined yet another paradigm for future Summer Technology Institutes. Maintaining the original goals from the previous two Institutes, the design of the upcoming program follows: 
1. Focus on one theme. In Summer Institute, 1996, the theme will be the World Wide Web as an instructional tool.

2. Form groups at the outset of the Institute. Group make-up should contain various levels of computer expertise, various levels of pedagogical expertise, diversity of discipline.

3. Participants should be present in the Institute throughout Phase One.

4. Teams work toward a group and individual project presentations.

5. During the Institute, random workshops are available to be attended as appropriate to each participant's needs.

6. A segment of each day addresses pedagogical issues: curriculum design and technology, syllabus design and technology, learning styles and technology.

7. Summer break is a better time for participants to learn the technology and pedagogy than during Winter break.

8. Group presentations and individual project presentations should not encompass one full day but rather range shorter time lengths over a greater number of days.

9. Incentive monies to purchase hardware and software of choice is meeting more university goals than laptop or Power book incentives.

10. Incorporate more Classroom Assessment Techniques (CATs) into the Institute design as well as teach CAT's that the participants can incorporate into their own classes in relation to technology, pedagogy and student learning objectives.

11. Encourage Institute participants to collect data during their classes in relation to technology and enhanced student learning.

\section{Conclusion}

Instructional technology concerns arise in every facet of academic life. This is evidenced by the quantity of publications addressing technology and pedagogy, conference strands that are devoted solely to technology, and the workshops around this issue. It is imperative that those who are most involved with teaching, change and campus culture become actively involved with how the introduction of technology into the classroom relates to each of the above. Centers for 
teaching and learning need to partner with the offices of instructional technology so that teachers incorporate technology as the value-added component into their teaching and that the ultimate goal is enhanced student learning.

\section{References}

Angelo, T.A. \& Cross, K.P. (1993). Classroom assessment techniques: A handbook for college teachers (2nd ed.). San Francisco: Jossey-Bass.

Liberal Education: Technology in Context (Summer, 1995). Association of American Colleges and Universities.

Shapiro, W.L., Roskos, K. \& Cartwright, G.P. (November/December, 1995). Technologyenhanced learning environments, Change, 67-69.

Technology in Higher Education (October, 1994). Center Associate: The Newsletter for Chief Academic Officers, 1(2),1-4.

\section{Contact:}

\section{Devorah A. Lieberman}

Center for Academic Excellence:

Instruction, Assessment \& Community Partnerships

Portland State University

P.O. Box 751

Portland, OR 97207-0751 USA

(503) 725-5642

(503) 725-5262 FAX

Devorah A. Lieberman is professor in the Department of Speech Communication and director of teaching and Learning Excellence in the Center for Academic Excellence at Portland State University. Her areas of research include intercultural communication and the effectiveness of technology in the learning environment.

John Rueter is professor in the Department of Biology and professor-in-residence at the Center for Academic Excellence at Portland State University. His areas of research include the study of algae and the effectiveness of educational technology in the learning environment. 